\title{
THE ROLE OF INFERIOR VENA CAVA DIAMETER VARIATION RATIO MEASURED BY ULTRASONOGRAPHY VERSUS CENTRAL VENOUS PRESSURE IN ASSESSMENT OF VOLUME RESPONSIVENESS OF SHOCKED HEPATIC PATIENTS
}

\author{
Raafat Abdelazim, Dina Salah, Rami M. Wahba, Mohammed M. Maarouf and \\ Mohamed Abdelwareth
}

\author{
Department of Anesthesia \& \\ Intensive Care and Pain \\ Management, Faculty of \\ Medicine - Ain Shams \\ University \\ Corresponds:
}

Mohamed Abdelwareth

\section{E.male:}

mohamedwareth85@gmail.com

Tel.: 01225472426

Received: 3/3/2019

Accepted: 28/3/2019

\begin{abstract}
:
Background: Liver cirrhosis is a major cause of morbidity and mortality in chronic liver disease patients which is multifactorial in nature, leading to several complications including ascites, variceal bleeding, hepatic encephalopathy and hepatorenal syndrome.
\end{abstract}

Aim of the study: to evaluate the relationship between inferior vena cava (IVC) diameter variation ratio measured by ultrasonography (USG) versus central venous pressure as measured via central venous catheter, and whether it is reliable for use in evaluating intravascular volume status during the management of shock in hepatic patients.

Patients and Methods: This study included one hundred cirrhotic liver patients with Child-Pugh classification $B$ and $C$ with acute circulatory failure of either sex, aging $\geq 18$ years old, admitted in the ICU at Ain Shams University hospitals. A standard resuscitation strategy was applied. The patients were monitored using mean arterial blood pressure (MAP), heart rate (HR), central venous pressure (CVP) and ultrasound guided IVC collapsibility index (IVCCI) simultaneously at baseline and along the subsequent stages of standard shock management protocol at intervals 1, 4 and 8 hours.

Results: The current study showed that 77 patients (77\%) responded to volume resuscitation with improvement as regard elevated MAP with maximal mean value of 67.34 ( \pm 4.01$) \mathrm{mmHg}$., decreased HR with minimal mean value of 103 ( \pm 4.89$)$ b/min., elevated central venous pressure with maximal mean value of $9.05( \pm 2.07) \mathrm{cmH}_{2} \mathrm{O}$ and decreased IVC-CI with minimal mean value of 0.64 ( \pm 0.05$)$ after 8 hours of volume management, these patients were considered volume responders., while 23 patients (23\%) didn't respond to volume resuscitation with no response or even deterioration as regard low MAP with maximal mean value of 49.61 ( \pm 3.56$) \mathrm{mmHg}$., high HR with minimal mean value of 133 ( \pm 4.86$)$ b/min., low central venous pressure with maximal mean value of 2.17 $( \pm 0.78) \mathrm{cmH}_{2} \mathrm{O}$ and low fixed IVC-CI with minimal mean value of 0.39 ( \pm 0.06$)$ after 8 hours of volume management, despite maximal possible volume of fluid resuscitation necessitating use of vasopressor agents, these patients were considered volume non responders.

Conclusion: Measurements of CVP and IVC-CI throughout the study in volume responder patients were found to have a solid negative correlation denoting that Inferior Vena Cava collapsibility index assessment is a safe option being non invasive technique and 


\section{Raafat Abdelazim, et al.,}

sensitive at least when compared to measuring CVP and to avoid complications of central venous line (CVL) insertion with its complications especially in hepatic patients with coagulopathy.

Key words: inferior vena cava diameter, ultrasonogaphy, central venous pressure, volume responsiveness of shocked hepatic patients

\section{INTRODUCTION:}

Cirrhotic patients are prone to develop life-threatening complications that require emergency care and intensive care unit (ICU) admission. They can present with specific decompensations related to cirrhosis such as variceal bleeding, hepatorenal syndrome (HRS) or other critical events that are observed in the general population such as severe sepsis or septic shock. Clinical management of all these entities requires a specific approach in cirrhosis ${ }^{(\mathbf{1})}$.

Cirrhotic patients have a hyperdynamic circulation with high cardiac output and low systemic vascular resistance in the absence of infection. Circulatory dysfunction increases the susceptibility of critically-ill cirrhotic patients to develop multiple organ failure and attenuates vascular reactivity to vasopressor drugs. Moreover, hypotensive cirrhotic patients require a carefully balanced replacement of volume status, since over transfusion increases portal hypertension and the risk of variceal bleeding and under transfusion causes tissue hypo perfusion which increases the risk of multiple organ failure ${ }^{(1)}$.

Therefore, it is essential to provide adequate fluid resuscitation without "overloading" in order to improve the outcome of the critically ill patients. This requires a careful assessment of the intravascular volume status and fluid responsiveness prior to the institution of fluid therapy ${ }^{(2)}$.

Central venous pressure (CVP) measurement is used to determine need for excess volume. An invasive method, such as central venous catheter placement, is required in order to measure the $\mathrm{CVP}^{(3)}$.
Catheter placement is one of the most commonly followed techniques at most hospitals to determine and interpret the CVP for assessing the fluid status; it's an invasive procedure, not easily done in an emergency setup, time consuming and difficult to maintain sterile precautions and has its own risks and complications. Complications such as arrhythmias, cardiac chamber injury, vascular-nerve injury, pneumothorax, hemothorax, local bleeding, hematoma, infection, thrombosis, occlusion, pulmonary embolism and post-phlebitic syndrome may occur with catheter placement ${ }^{(4)}$.

Bedside ultrasound (BUS) is being increasingly used by the intensivists to assess the intravascular volume status and fluid responsiveness by measuring inferior vena cava (IVC) diameter and variation in IVC diameter in relation to respiration ${ }^{(2)}$. It is simple, noninvasive and can be used for repeated assessment ${ }^{(5)}$.

Changes in volume status will be reflected in sonographic evaluation of the IVC, where increased or decreased collapsibility of the vessel will help guide clinical management of the patient. The combination of the absolute diameter of the IVC and the degree of collapse with respiration may give an estimate of CVP and substitute for more invasive measurements ${ }^{(\mathbf{6})}$.

\section{AIM OF THE STUDY:}

The aim of this study is to evaluate the relationship between inferior vena cava (IVC) diameter variation ratio measured by ultrasonography (USG) versus central venous pressure as measured via central venous catheter, and whether it is reliable for 
use in evaluating intravascular volume status during the management of shock in hepatic patients.

\section{PATIENTS AND METHODS:}

One hundred cirrhotic liver patients with Child-Pugh classification $\mathrm{B}$ and $\mathrm{C}$ with acute circulatory failure as described later of either sex, aging $\geq 18$ years old, admitted in the ICU at Ain Shams University hospitals during the last two years, were enrolled in the non-probability consecutive sampling after the approval of the Research Ethical Committee of faculty of medicine Ain Shams University and obtaining a written informed consent from the patient or the $1^{\text {st }}$ degree relatives in case of encephalopathic patient.

\section{Exclusion criteria:}

Patients with the following criteria were excluded from the study:

Patients who needed mechanical ventilation, Deeply comatose patients (encephalopathy grade IV) with Glasgow coma scale $\leq 8 / 15$, who were in need of mechanical ventilation. Inconvenience of technique as in: intra-abdominal pressure over $12 \mathrm{~cm} \mathrm{H}_{2} \mathrm{O}$ (tense ascites) assessed by indwelling urinary catheter to measure the intravesical pressure, patients in whom we could not visualize the inferior vena cava due to the large body habitus BMI $>40$ $\mathrm{Kg} / \mathrm{m}^{2}$ or excessive intra-abdominal bowel gas, massive pleural effusion, pneumo or hemothorax. Severe tricuspid valve regurge with mean pulmonary artery pressure more than $50 \mathrm{mmHg}$ by transthoracic echocardiography, denoting cardiac right side dysfunction with subsequent systemic venous congestion. Neck and upper chest burns, previous neck radiotherapy or local site infection at site of CVL insertion.

\section{Assessment:}

All patients included in the study were assessed by: Patients' demographic data: age, sex, body weight and height, detailed medical and surgical history, complete clinical examination, routine laboratory investigations and serum lactate, chest x-ray and standard 12 lead electrocardiogram (ECG).

\section{Monitoring:}

Standard monitoring was applied, including non-invasive arterial blood pressure, electrocardiography and pulse oximetry using the multichannel monitor.

\section{Technique:}

Patients were examined in supine position, with the bed flat. The basic monitors (ECG, NIBP and $\mathrm{SpO}_{2}$ ) were attached. All patients were shocked with MAP $<60 \mathrm{mmHg}$, and HR $>120$ beat $/ \mathrm{min}$. All patients were spontaneous breathers.

CVP catheters were inserted in all patients either through internal jugular or subclavian vein under complete aseptic technique and assured it was in place by doing chest $\mathrm{x}$-ray. All the readings were taken by intensive care physician and assistant nurse. Data were collected before start of fluid therapy and after 1, 4 and 8 hours.

Ultrasound machine was used to measure diameter. A $17 \mathrm{~mm}$ curved probe and cardiac transducer for IVC imaging 1-5 $\mathrm{MHz} ; 21 \mathrm{~mm}$ phase array was used.

We measured maximum anteroposterior diameter of IVC (IVCd-max) at end expiration just caudal to the confluence of the hepatic veins in longitudinal plane using $M$ mode and leading edge technique (inner edge to inner edge of vessel wall). In addition minimum IVC diameter (IVCdmin) was measured at end inspiration during normal spontaneous breathing.

Subxiphoid approach was used to visualize IVC. All the readings were taken by intensive care physician, who had received a training course Physician sought in use of bed site ultrasonography. Data 
were collected before start of fluid therapy and after 1, 4 and 8 hours. All data collected were analyzed using Minitab ${ }^{\circledR}$ 17.3.1.

\section{Measurements:}

1. Hemodynamic parameters (HR and MAP) were monitored before start of fluid therapy and after 1, 4 and 8 hours.

2. Central venous pressure (CVP): A transducer used to measure the central venous pressure was fixed at the level of the patient's phlebostatic axis, the level at which the fourth intercostal space meets the midaxillary line (normal value between 5 to $10 \mathrm{~cm} \mathrm{H}_{2} \mathrm{O}$ ). After zeroing, the transducer was left open to the central venous catheter. CVP waveform displayed on the monitor with the average central venous pressure measured continuously in $\mathrm{cm}_{2} \mathrm{O}$. This measurement was taken by the same intensive care physician and assistant nurse.

3. Clinical assessment for signs of hypovolemia: Hypotension: defined as mean arterial blood pressure $<60 \mathrm{mmHg}$ in two consecutively reading with an interval of two minutes, by using noninvasive technique. Tachycardia: $>120$ beat/minute, prolongation of capillary refill $>3$ seconds, acidosis and increased serum lactate $>2 \mathrm{mmol} / \mathrm{L}$.

4. Ultrasound measurements including: Maximum IVC diameter at end expiration (IVCdmax): in centimeters to measure the IVC diameter, a curvilinear probe of SonoSite turbo ultrasound machine was placed longitudinally in the subxiphoid region with the probe marker to the patient's head, to visualize the confluence of the hepatic veins draining into the IVC. We may need to move the probe $1-2 \mathrm{~cm}$ to the patient's right and then tilt it slightly towards the heart. The internal anterior posterior [AP] diameter of the IVC just caudal to the confluence of the hepatic veins in the longitudinal plane was measured.

The IVC diameter variation ratio or IVC collapsibility index (IVC CI): It is the difference between the maximum (normal value between 1.7 to $2.5 \mathrm{~cm}$.) and minimum IVC diameters (normal value between 1.0 to $1.5 \mathrm{~cm}$.) divided by the maximum IVC diameter, expressed as ([IVCdmax IVCdmin] / IVCdmax). Normal range of IVC-CI ranging between 0.2 to 0.6 , values more than 0.6 suggest hypovolemia and values less than 0.2 suggest loss of IVC contractions as in hypervolemia or vasoplegia. The previous measurements were recorded in a spontaneously breathing patient at the following timings: Baseline measurement before start of fluid therapy, after 1, 4 and 8 hours of start of fluid resuscitation.

\section{Resuscitation strategy in shocked cirrhotic patients include:}

1. Use of crystalloid solutions as the initial fluid of choice in volume depleted patients $(10-20 \mathrm{ml} / \mathrm{kg})$, either normal $0.9 \%$ saline or balanced salt solutions (such as Ringer acetate solution) which may be preferred to than normal saline in patients with hyperchloremic acidosis, and in patients with relative hyperchloremia (e.g. those with "normal" chloride in the setting of low serum sodium).

2. Use of albumin ( $8 \mathrm{~g} / \mathrm{L}$ of ascites removed) following large volume paracentesis $(>5 \mathrm{~L})$.

3. Patients with spontaneous bacterial peritonitis (SBP) should receive concentrated albumin $(1.5 \mathrm{~g} / \mathrm{kg})$, as albumin use in patients with cirrhosis and SBP was shown to prevent hepatorenal syndrome and to improve systemic hemodynamics and survival.

4. Patients with suspected bacterial infection fluid resuscitation with crystalloids and a proportion of $4-5 \%$ 
albumin, the beneficial effects of human serum albumin have been traditionally attributed to plasma volume expansion, they could also relate to its effects modulating systemic and organ inflammation.

5. Avoid use of hydroxyethyl starch.

After administration of fluid bolus crystalloid, patient was defined as fluid responder if the mean arterial pressure increased by at least $20 \%$ as compared with pre-fluid challenge values. If there is no or a little response to volume resuscitation in the form of low MAP $\leq 60 \mathrm{mmHg}$, high $\mathrm{HR} \geq$ $120 \mathrm{~b} / \mathrm{min}$, loss of IVC diameter variability and low central venous pressure within initial $1^{\text {st }}$ hour of management till 8 hours despite maximal resuscitation volume, consider start of vasopressor infusion. This is the end point of the present study. Noradrenaline is considered $1^{\text {st }}$ choice vasopressor agent, with starting dose 50 $\mathrm{ng} / \mathrm{kg} / \mathrm{min}$, then adjust dose according to hemodynamic response to keep mean arterial pressure between 70 to $90 \mathrm{mmHg}$.

\section{Sample size calculation:}

Alpha error $=0.05$ (two-sided).

Power of study $=0.8$

Based on preinfusion caval index.

p 1 US percentage of high pre infusion caval index in responders $=61 \%$.

p 2 US percentage of high pre infusion caval index in non responders $=31 \%$.

Estimated required sample size:

$\mathrm{N}=100$ patients.

50 patients in each group.

Program for sample size calculation is Stata 10.

\section{Statistical analysis:}

Recorded data were analyzed using the software Minitab ${ }^{\circledR}$ 17.3.1. Quantitative sample data was expressed as mean \pm standard deviation (SD). Raw data of the test group was divided into two subgroups based on responding to resuscitation measures. These two sets are the group of responders (R) and the group of nonresponders (NR).

\section{The following tests were done:}

- Independent-samples t-test of significance was used when comparing between the means of the responder group and the non-responder group with reference to each of mean arterial pressure, heart rate, central venous pressure and caval index.

- Paired sample t-test of significance was used when comparing the result sets of mean arterial pressure, heart rate, central venous pressure and caval index when recorded over varying time intervals (baseline, after 1, 4,and 8 hours). The test is performed within each of the groups of either responder or nonresponder subjects.

- Pearson's correlation coefficient (r) test was used to assess the degree of association between two sets of variables.

- The confidence level was set to $95 \%$ and the margin of error accepted was set to $5 \%$. So, the p-value was considered significant if $<0.05$.

\section{RESULTS:}

\section{Sample descriptive statistics}

Table (1): Demographic data distribution.

\begin{tabular}{|l|c|}
\hline \multicolumn{2}{|l|}{ Demographic data } \\
\hline Sex $\begin{array}{r}\text { Male 53 (53\%) } \\
\text { Female 47 (47\%) }\end{array}$ \\
\hline & Mean $\pm(\mathrm{SD})$ \\
\hline Age (years) & $52.16 \pm 6.61$ \\
\hline Weight $(\mathrm{kg})$ & $79.14 \pm 9.01$ \\
\hline Height $(\mathrm{cm})$ & $169.23 \pm 6.55$ \\
\hline BMI $\left(\mathrm{Kg} / \mathrm{m}^{2}\right)$ & $27.62 \pm 1.99$ \\
\hline
\end{tabular}


II. Hemodynamic variables:

\section{Mean arterial pressure (MAP):}

- The volume responders showed progressive increase overtime in MAP values in response to volume resuscitation as indicated in table (2).

Table (2): MAP changes in volume responder patients in response to volume resuscitation over time periods of management.

\begin{tabular}{|l|c|c|c|c|}
\hline $\begin{array}{c}\text { MAP } \\
(\mathrm{mmHg})\end{array}$ & Mean $\pm \mathrm{SD}$ & $\begin{array}{c}\text { Mean diff. from } \\
\text { baseline }\end{array}$ & Paired test & p-value \\
\hline Baseline & $54.68 \pm 4.07$ & & & \\
\hline After $1 \mathrm{hr}$ & $59.62 \pm 3.95$ & -4.94 & -17.69 & 0.000 \\
\hline After 4hrs & $63.34 \pm 7.06$ & -8.66 & -27.44 & 0.000 \\
\hline After $8 \mathrm{hrs}$ & $67.34 \pm 4.01$ & -12.66 & -35.77 & 0.000 \\
\hline
\end{tabular}

- The volume non-responders showed significant, in response to volume statistically significant decrease in MAP, resuscitation as indicated in table (3).

however these changes are clinically non

Table (3): MAP changes in volume non responder patients in response to volume resuscitation over time periods of management.

\begin{tabular}{|c|c|c|c|c|}
\hline $\begin{array}{c}\text { MAP } \\
(\mathrm{mmHg})\end{array}$ & Mean $\pm \mathrm{SD}$ & $\begin{array}{c}\text { Mean diff. } \\
\text { from baseline }\end{array}$ & Paired test & p-value \\
\hline Baseline & $54.70 \pm 2.49$ & & & \\
\hline After 1hr & $51.44 \pm 3.33$ & 3.26 & 5.55 & 0.00 \\
\hline After 4hrs & $50.44 \pm 3.04$ & 4.26 & 6.26 & 0.000 \\
\hline After 8hrs & $49.61 \pm 3.56$ & 5.09 & 5.53 & 0.00 \\
\hline
\end{tabular}

- Table (4) shows the difference between volume responder and non-responder group when mean arterial pressure readings were tested for significance using two sample t-test at different time intervals. There was no significant

difference between both groups at zero time (baseline). In the volume responder group, the MAP was significantly higher compared with the volume non responder group at time intervals 1,4 and 8 hours.

Table (4): Comparison between responder and non-responder according to MAP.

\begin{tabular}{|l|c|c|c|c|}
\hline \multicolumn{1}{|c|}{ MAP (mmHg) } & $\begin{array}{c}\text { Responder } \\
(n=77)\end{array}$ & $\begin{array}{c}\text { Non } \\
\text { Responder } \\
(n=23)\end{array}$ & t-test & p-value \\
\hline Baseline & $54.68 \pm 0.47$ & $54.70 \pm 2.49$ & 0.03 & 0.977 \\
\hline After 1hr & $59.62 \pm 3.85$ & $51.43 \pm 3.33$ & -9.97 & 0.000 \\
\hline After 4hrs & $63.34 \pm 3.95$ & $50.43 \pm 3.04$ & -16.58 & 0.000 \\
\hline After 8 hrs & $67.34 \pm 4.10$ & $49.61 \pm 3.56$ & -20.20 & 0.000 \\
\hline
\end{tabular}

Values are mean \pm SD.

\section{Heart rate (HR):}

- The volume responders showed progressive decrease overtime in HR

values in response to volume resuscitation as indicated in table (5). 
Table (5): HR changes in volume responder patients in response to volume resuscitation over time periods of management

\begin{tabular}{|l|c|c|c|c|}
\hline HR (Beat/min) & Mean $\pm \mathrm{SD}$ & $\begin{array}{c}\text { Mean diff. from } \\
\text { baseline }\end{array}$ & $\begin{array}{c}\text { Paired } \\
\text { test }\end{array}$ & p-value \\
\hline Baseline & $129.00 \pm 6.28$ & & & \\
\hline After $1 \mathrm{hr}$ & $118.56 \pm 6.82$ & 10.44 & 22.28 & 0.000 \\
\hline After 4hrs & $111.82 \pm 5.98$ & 17.18 & 32.66 & 0.000 \\
\hline After $8 \mathrm{hrs}$ & $103.14 \pm 4.89$ & 25.86 & 41.11 & 0.000 \\
\hline
\end{tabular}

- The volume non-responders showed statistically non significant change in

heart rate values in response to volume resuscitation as indicated in table (6).

Table (6): HR changes in volume non responder patients in response to volume resuscitation over time periods of management.

\begin{tabular}{|l|c|c|c|c|}
\hline $\begin{array}{c}\mathrm{HR} \\
(\text { Beat } / \mathrm{min})\end{array}$ & Mean $\pm \mathrm{SD}$ & $\begin{array}{c}\text { Mean diff. from } \\
\text { baseline }\end{array}$ & Paired test & $\mathrm{p}$-value \\
\hline Baseline & $131.04 \pm 5.09$ & & & \\
\hline After $1 \mathrm{hr}$ & $129.39 \pm 4.96$ & 1.65 & 1.47 & 0.157 \\
\hline After 4hrs & $131.52 \pm 4.45$ & -0.48 & -0.53 & 0.60 \\
\hline After $8 \mathrm{hrs}$ & $133.00 \pm 4.86$ & -1.96 & -2.05 & 0.052 \\
\hline
\end{tabular}

Table (7) shows the difference between volume responder and non-responder group when heart rate readings were tested for significance using two sample t-test at different time intervals. There was no significant difference between both groups at zero time (baseline). In the volume responder group the HR was significantly lower compared with the volume non responder group at time intervals 1,4 and 8 hours.

Table (7): Comparison between responder and non-responder according to heart rate.

\begin{tabular}{|l|c|c|c|c|}
\hline \multicolumn{1}{|c|}{ HR (Beat/min) } & $\begin{array}{c}\text { Responder } \\
(n=77)\end{array}$ & $\begin{array}{c}\text { Non } \\
\text { Responder } \\
(n=23)\end{array}$ & t-test & p-value \\
\hline Baseline & $129.00 \pm 6.28$ & $131.04 \pm 5.09$ & 1.60 & 0.118 \\
\hline After 1hr & $118.56 \pm 6.82$ & $129.39 \pm 4.96$ & 8.37 & 0.000 \\
\hline After 4hrs & $111.82 \pm 5.98$ & $131.52 \pm 4.45$ & 17.12 & 0.000 \\
\hline After 8hrs & $103.14 \pm 4.89$ & $133.00 \pm 4.86$ & 25.81 & 0.000 \\
\hline
\end{tabular}

Values are mean \pm SD.

\section{Central venous pressure (CVP):}

The volume responders showed progressive increase overtime in CVP values in response to volume resuscitation as indicated in table (8).

Table (8): CVP changes in volume responder patients in response to volume resuscitation over time periods of management.

\begin{tabular}{|l|c|c|c|c|}
\hline $\begin{array}{c}\mathrm{CVP} \\
\left(\mathrm{cm} \mathrm{H} \mathrm{H}_{2} \mathrm{O}\right)\end{array}$ & Mean $\pm \mathrm{SD}$ & $\begin{array}{c}\text { Mean diff. } \\
\text { from baseline }\end{array}$ & Paired test & p-value \\
\hline Baseline & $1.88 \pm 1.55$ & & & \\
\hline After 1hr & $3.95 \pm 1.72$ & -2.07 & -22.19 & 0.000 \\
\hline After 4hrs & $6.22 \pm 1.85$ & -4.34 & -29.48 & 0.000 \\
\hline After $8 \mathrm{hrs}$ & $9.05 \pm 2.07$ & -7.17 & -35.05 & 0.000 \\
\hline
\end{tabular}


$>$ In response to volume resuscitation, the volume non-responder group showed a statistically significant increase in central venous pressure values at 4 hour compared to baseline values, however these changes are clinically non significant as indicated in table (9).

Table (9): CVP changes in volume non responder patients in response to volume resuscitation over time periods of management.

\begin{tabular}{|l|c|c|c|c|}
\hline $\begin{array}{c}\mathrm{CVP} \\
\left(\mathrm{cm} \mathrm{H} \mathrm{H}_{2} \mathrm{O}\right)\end{array}$ & Mean $\pm \mathrm{SD}$ & $\begin{array}{c}\text { Mean diff. } \\
\text { from baseline }\end{array}$ & Paired test & p-value \\
\hline Baseline & $1.78 \pm 0.60$ & & & \\
\hline After 1hr & $1.74 \pm 1.10$ & 0.04 & 0.20 & 0.847 \\
\hline After 4hrs & $2.17 \pm 0.78$ & -0.39 & -2.40 & 0.025 \\
\hline After $8 \mathrm{hrs}$ & $1.96 \pm 1.55$ & -0.17 & -0.58 & 0.496 \\
\hline
\end{tabular}

Table (10) shows the difference between volume responder and non-responder group when CVP readings were tested for significance using two sample t-test at different time intervals. There was no significant difference between the mean of both groups at baseline. In the volume responder group, the CVP was significantly higher than the volume non responder group at time intervals 1,4 and 8 hours.

Table (10): Comparison between responder and non-responder according to CVP.

\begin{tabular}{|l|c|c|c|c|}
\hline \multicolumn{1}{|c|}{$\mathrm{CVP}\left(\mathrm{cm} \mathrm{H}_{2} \mathrm{O}\right)$} & $\begin{array}{c}\text { Responder } \\
(n=77)\end{array}$ & $\begin{array}{c}\text { Non } \\
\text { Responder } \\
(n=23)\end{array}$ & t-test & p-value \\
\hline Baseline & $1.88 \pm 1.55$ & $1.783 \pm 0.60$ & -0.46 & 0.643 \\
\hline After 1hr & $3.95 \pm 1.72$ & $1.74 \pm 1.10$ & -7.33 & 0.000 \\
\hline After 4hrs & $6.22 \pm 1.85$ & $2.174 \pm 0.78$ & -15.19 & 0.000 \\
\hline After 8hrs & $9.05 \pm 2.07$ & $1.96 \pm 1.55$ & -17.72 & 0.000 \\
\hline
\end{tabular}

Values are mean $\pm \mathrm{SD}$.

\section{Inferior vena cava collapsibility index (IVC-CI):}

values in response to volume resuscitation as indicated in table (11).

$>$ The volume responders showed progressive decrease overtime in CI

Table (11): IVC-CI changes in volume responder patients in response to volume resuscitation over time periods of management.

\begin{tabular}{|l|c|c|c|c|}
\hline \multicolumn{1}{|c|}{$\mathrm{CI}$} & Mean $\pm \mathrm{SD}$ & $\begin{array}{c}\text { Mean diff. } \\
\text { from baseline }\end{array}$ & Paired test & p-value \\
\hline Baseline & $0.77 \pm 0.03$ & & & \\
\hline After 1hr & $0.73 \pm 0.026$ & 0.04 & 21.94 & 0.000 \\
\hline After 4hrs & $0.70 \pm 0.029$ & 0.07 & 26.27 & 0.000 \\
\hline After 8hrs & $0.64 \pm 0.05$ & 0.13 & 25.93 & 0.000 \\
\hline
\end{tabular}

$>$ In response to volume resuscitation, the volume non-responder group showed a statistically significant decrease in CI values at 4 and 8 hours compared to baseline values, however these changes are clinically non significant as indicated in table (12). 
Table (12): IVC-CI changes in volume non responder patients in response to volume resuscitation over time periods of management.

\begin{tabular}{|l|c|c|c|c|}
\hline \multicolumn{1}{|c|}{$\mathrm{CI}$} & Mean $\pm \mathrm{SD}$ & $\begin{array}{c}\text { Mean diff. } \\
\text { from baseline }\end{array}$ & Paired test & p-value \\
\hline Baseline & $0.77 \pm 0.03$ & & & \\
\hline After 1hr & $0.73 \pm 0.026$ & 0.04 & 21.94 & 0.000 \\
\hline After 4hrs & $0.70 \pm 0.029$ & 0.07 & 26.27 & 0.000 \\
\hline After 8hrs & $0.64 \pm 0.05$ & 0.13 & 25.93 & 0.000 \\
\hline
\end{tabular}

Table (13) shows the difference between volume responder and non-responder group when CI readings were tested for significance using two sample t-test at Table (13): Comparison between responder and non-responder according to IVC-CI.

\begin{tabular}{|c|c|c|c|c|}
\hline CI & $\begin{array}{c}\text { Responder } \\
(n=77)\end{array}$ & $\begin{array}{c}\text { Non Responder } \\
(n=23)\end{array}$ & $\mathrm{t}$-test & $\mathrm{p}$-value \\
\hline Baseline & $0.77 \pm 0.03$ & $0.46 \pm 0.06$ & -22.81 & 0.000 \\
\hline After 1hr & $0.73 \pm 0.03$ & $0.44 \pm 0.05$ & -29.73 & 0.000 \\
\hline After 4hrs & $0.70 \pm 0.03$ & $0.42 \pm 0.05$ & -26.23 & 0.000 \\
\hline After 8hrs & $0.64 \pm 0.05$ & $0.39 \pm 0.06$ & -19.59 & 0.000 \\
\hline
\end{tabular}

Values are mean \pm SD.

III. Correlation between CVP and IVCCI:

Measurements of CVP and IVC-CI throughout the study in volume responder patients were found to be strongly correlated. This was evident in calculating Pearson coefficient; a value of $(-0.97)$ to (0.98) throughout the measurement periods, denoting a solid negative correlation different time intervals. There was significant difference between both groups at different time points. between CVP and IVC-CI that is highly significant.

Pearson Correlation shows the strength of linear relationship between two variables; negative correlation means that when one variable runs in a direction the paired one runs in the other direction. It ranges from -1 to +1 and when (r) value becomes near the value 1 or -1 , it indicates the stronger linear relationship as indicated in table 14 .

Table (14): Correlation between CVP $\left(\mathrm{cmH}_{2} \mathrm{O}\right)$ and Caval index over the periods, using Pearson Correlation Coefficient in volume responders.

\begin{tabular}{|l|c|c|c|c|}
\hline & $\mathrm{CVP}\left(\mathrm{cmH}_{2} \mathrm{O}\right)$ & $\mathrm{CI}$ & \multicolumn{2}{c|}{$\begin{array}{c}\mathrm{CVP}\left(\mathrm{cmH}_{2} \mathrm{O}\right) \& \\
\text { Caval Index }\end{array}$} \\
\hline Time & Mean $\pm \mathrm{SD}$ & Mean $\pm \mathrm{SD}$ & $\mathrm{r}$ & $\mathrm{p}$-value \\
\hline Baseline & $1.88 \pm 1.55$ & $0.77 \pm 0.03$ & -0.94 & 0.000 \\
\hline After 1hr & $3.95 \pm 1.72$ & $0.73 \pm 0.03$ & -0.96 & 0.000 \\
\hline After 4hrs & $6.22 \pm 1.85$ & $0.70 \pm 0.03$ & -0.94 & 0.000 \\
\hline After 8hrs & $9.05 \pm 2.07$ & $0.64 \pm 0.05$ & -0.98 & 0.000 \\
\hline
\end{tabular}

Measurements of CVP and IVC-CI throughout the study in volume non responder patients were found to be not correlated. This was evident in calculating Pearson coefficient; a value of $(-0.095)$ to
(0.356) was found throughout the measurement periods with no linear relationship between the two variables as indicated in table 15 . 
Table (15): Correlation between CVP $\left(\mathrm{cmH}_{2} \mathrm{O}\right)$ and Caval index over the study periods, using Pearson Correlation Coefficient in volume non responders.

\begin{tabular}{|l|c|c|c|c|}
\hline & CVP $\left(\mathrm{cmH}_{2} \mathrm{O}\right)$ & $\mathrm{CI}$ & \multicolumn{2}{c|}{$\begin{array}{c}\mathrm{CVP}\left(\mathrm{cmH}_{2} \mathrm{O}\right) \& \\
\text { Caval Index }\end{array}$} \\
\hline Time & Mean \pm SD & Mean \pm SD & r & p-value \\
\hline Baseline & $1.78 \pm 0.60$ & $0.46 \pm 0.06$ & 0.356 & 0.096 \\
\hline After 1hr & $1.74 \pm 1.10$ & $0.44 \pm 0.05$ & 0.149 & 0.498 \\
\hline After 4hrs & $2.17 \pm 0.78$ & $0.42 \pm 0.05$ & 0.177 & 0.420 \\
\hline After 8hrs & $1.96 \pm 1.55$ & $0.39 \pm 0.06$ & -0.095 & 0.666 \\
\hline
\end{tabular}

\section{DISCUSSION:}

Traditionally the central venous pressure (CVP) has been used to guide fluid management. A Canadian survey reported that $90 \%$ of intensivists use the CVP to monitor fluid resuscitation in patients with septic shock. The CVP is a good approximation of right atrial pressure, which is a major determinant of right ventricular (RV) filling. However, due to the changes in venous tone, intrathoracic pressures, LV and RV compliance, and geometry that occur in critically ill patients, there is a poor relationship between the CVP and RV enddiastolic volume. Furthermore, the RV enddiastolic volume may not reflect the patients' position on the Frank-Starling curve and therefore his/her preload reserve ${ }^{(7)}$.

The presence of an "extreme" CVP value may be more helpful to guide fluid administration than intermediate values. In a recent systematic review by Eskesen and his colleagues in 2016 including 1148 patients from 51 studies that evaluated the response to a fluid bolus and reported CVP, the overall predictive value of CVP was poor ${ }^{(\mathbf{8})}$.

This study was done at Ain Shams University hospitals; included 100 shocked cirrhotic liver patients admitted in the intensive care unit and revealed two types of response to fluid resuscitation. Most patients (77 patients of 100) showed improvement with volume resuscitation as regard vital data improvement, elevated central venous pressure with maximal mean value 9.05( \pm 2.07$) \mathrm{cmH}_{2} \mathrm{O}$ after 8 hours of volume management and decreased IVC- CI with maximal mean value $0.64( \pm 0.05)$ after 8 hours of volume management, these patients are considered volume responders.

However, some patients (23 patients of 100) showed no response or even deterioration with volume resuscitation as regard vital data deterioration, low central venous pressure with maximal mean value $1.96( \pm 1.55) \mathrm{cmH}_{2} \mathrm{O}$ after 8 hours of volume management and low mostly fixed IVC-CI with maximal mean value $0.39( \pm 0.06)$ after 8 hours of volume management, despite maximal possible volume of fluid resuscitation necessitating use of vasopressor agents, these patients are considered volume non responders.

Among fluid responder patients, there was a solid negative correlation between the central venous pressure and the IVC-CI in the form of caval index value decline with central venous pressure increase during patient resuscitation with subsequent vital data improvement, denoting that measurement of the IVC-CI is a good non invasive indicator of fluid responsiveness in shocked hepatic patients.

While among volume non responder patients, there was a low fixed caval index value with low central venous pressure during patient resuscitation with no subsequent hemodynamic improvement, denoting that measurement of the IVC-CI is a good non invasive indicator of vasopressor agent start in shocked cirrhotic patients.

This study shows a statistically significant lower heart rate in volume 
responder patients compared to nonresponders, in response to resuscitation with average HR of $103 \mathrm{bpm}$ after 8 hours in responder group and average $\mathrm{HR}$ of 133 bpm after 8 hours in non responder patients. So, HR responsiveness to bolus resuscitation is considered as good negative test to decide volume responsiveness. However, decrease in heart rate wasn't observed even in some patients in the volume responders. This might be explained by the fact that the causes of tachycardia are numerous and varied in our patients selection e.g. sepsis and hyperdynamic circulation.

This study shows a statistically significant increase of CVP for responder group compared to non-responder, the group of patients who responded to fluid resuscitation had higher CVP values (mean 9 $\mathrm{Cm}_{2} \mathrm{O}$ after 8 hours) in contrast to lower CVP values in non responder group (mean CVP $1.96 \mathrm{~cm} \mathrm{H}_{2} \mathrm{O}$ after 8 hours) with pvalue $<0.05$.

This also can be correlated with low caval index in non responder group when compared to higher caval index in responder group.

In a study by de Valley and his colleagues $^{(9)}$ carried on 45 shocked patients, the IVC-CI was determined immediately and after $500 \mathrm{ml} \mathrm{NaCl} 0.9 \%$ was administered in 15 minutes. The clinical response was observed. An adequate response was defined as an increase in systolic blood pressure of at least $10 \mathrm{~mm} \mathrm{Hg}$. Based on this definition patients were divided into responders and non-responders. A low IVC-CI $(<0.37)$ in patients with signs of shock reliably predicted the absence of an adequate response to fluid therapy (negative predictive value 0.92). The positive predictive value of a high IVC-CI was much lower $(0.48)$ despite the fact that responders had a significantly higher pre-infusion IVCCI than non-responders (0.49 vs.0. $32, p$ 0.014). An explanation for the absence of a blood pressure response in the group of patients with a higher IVC-CI than normal range might be that these patients represent a group requiring more volume therapy than $500 \mathrm{ml}$.

Yanagawa and his colleagues ${ }^{(\mathbf{1 0})}$ measured IVC diameters in 35 trauma patients, with 10 of them in shock and 25 in a stable hemodynamic state, in emergency department. In this study, the IVC diameter at the end of expiration was measured in trauma patients with hemorrhagic shock at baseline and again after what was believed to be adequate fluid resuscitation (defined by the improvement of systolic blood pressure to a level greater than $90 \mathrm{~mm} \mathrm{Hg}$ ). Individuals who were able to maintain a stable blood pressure after fluid resuscitation had a significant diameter increase in end-expiratory IVC, whereas those who remained hemodynamically unstable did not have a change in IVC diameter with resuscitation. The authors concluded that changes in IVC diameter in response to fluid resuscitation is a better indicator of adequate fluid resuscitation than vital signs.

The current study shows a significant negative correlation between CVP $\left(\mathrm{cmH}_{2} \mathrm{O}\right)$ and IVC-CI over the periods of one, four and eight hours after baseline measurement in the study group by Pearson Correlation coeffient $(r=-0.9)$ with $p$-value $<0.05$.

A prospective double-blind observational study by Worapratya and his colleagues in $2014^{(11)}$ was conducted in the emergency room of a tertiary care center on shocked patients. The IVC-CI was calculated. The correlation of CVP and the IVC-CI were calculated by Pearson's correlation coefficient among the 30 patients. The correlations of the CVP measurement with the ultrasound IVC IVCCI were $r=-0.721 \quad(P=0.000)$ by 2D-mode ultrasound and $r=-0.647(P=0.001)$ by $\mathrm{M}$ mode. This study concluded that the IVCCI measured by bedside ultrasound in the 
emergency room had a good correlation with CVP, a result that resonates with the current study results.

Another study was carried in Al-Azhar University by Shalaby and his colleagues ${ }^{(\mathbf{1 2})}$ to evaluate the correlation between central venous pressure (CVP) measurements and ultrasound measurements of the inferior vena cava diameter, and collapsibility index (IVC-CI), aiming to evaluate the ultrasound as a noninvasive tool in assessment of intravascular volume status and fluid responsiveness in critically ill intensive care unit patients. Fifty patients aged $30-60$ years were involved in this single blinded correlational study. A significant negative correlation between CVP and IVC CI ( $\mathrm{r}=$ $0.788, p<0.001$ ) showed that inferior vena cava collapsibility index (IVC CI) had the most favorable performance in predicting CVP $<10 \mathrm{~cm} \mathrm{H}_{2} \mathrm{O}$.

A cross-sectional study by Ilyas and his colleagues $^{(\mathbf{1 3})}$ used the convenient sampling of 100 adult medical intensive care unit (ICU) patients for a period of three months. Patients $\geq 18$ years of age with total of $32 / 100(32 \%)$ females and 68/100 (68\%) males were included in the study with a mean age of $50.4 \pm 19.3$ years. The mean central venous pressure maintained was $10.38( \pm 4.14) \mathrm{cmH}_{2} \mathrm{O}$ with an inferior vena cava collapsibility index of $30.68( \pm 10.93)$. There was a statistically significant relation between the mean CVP pressure, the IVC collapsibility index, the mean maximum and minimum IVC between groups as determined by one-way analysis of variance (ANOVA) $(\mathrm{p}<0.001)$. There was a strong negative correlation between CVP and IVC collapsibility index (\%), which was statistically significant $(\mathrm{r}=-0.827, \mathrm{n}=100$, $\mathrm{p}<0.0005)$. A strong positive correlation between CVP and maximum IVC diameter $(\mathrm{r}=0.371, \mathrm{n}=100, \mathrm{p}<0.0005)$ and minimum IVC diameter $(\mathrm{r}=0.572, \mathrm{n}=100$, $\mathrm{p}<0.0005$ ) was found.

\section{Conclusion:}

Inferior Vena Cava collapsibility index assessment is relatively safe option being non invasive technique and sensitive at least when compared to measuring CVP and to avoid complications of central venous line (CVL) insertion with its complications especially in cirrhotic patients with coagulopathy.

However, depending on Inferior Vena Cava collapsibility index measurement may be used with caution in patients with high intrathoracic or intraabdominal pressures as the IVC-CI measurement might be less reliable.

Based on our study we recommend evaluating intravascular volume status in hepatic patients using IVC-CI measurement instead of CVP measurement via CVL insertion.

\section{REFERENCES:}

1. Ginès $P$, Fernandez $J$, Durand $F$ and Saliba F (2012): Management of critically-ill cirrhotic patients. J Hepatol; 56 Suppl 1:S13-24.

2. Kitakule MM and Mayo P (2010): Use of ultrasound to assess fluid responsiveness in the intensive care unit. Open Crit Care Med J; 3:33-37.

3. Johansson E, Hammarskjöld F, Lundberg D and Arnlind MH (2013): Advantages and disadvantages of peripherally inserted central venous catheters (PICC) compared to other central venous lines: a systematic review of the literature. Acta Oncol; 52(5): 886-892.

4. Nayeemuddin M, Pherwani AD, Asquith JR (2013): Imaging and management of complications of central venous catheters. Clin Radiol; 68:529-544.

5. Carr BG, Dean AJ, Everett WW and Ku BS, Mark DG, Okusanya O, Horan AD and Gracias VH (2007): Intensive's bedside ultrasound (INBU) for volume assessment in the intensive care unit: a pilot study. J Trauma Sep; 63(3):495-500. 
6. Goldflam K, Saul $\mathrm{T}$ and Lewiss $\mathrm{R}$ (2011): ACEP Policy Statement on Emergency Ultrasound Guidelines. Ann Emerg Med; 53:550-570.

7. Marik PE, Baram M, Vahid B (2008): Does central venous pressure predict fluid responsiveness? A systematic review of the literature and the tale of seven mares. Chest; 134: $172-178$.

8. Eskesen TG, Wetterslev M, Perner A (2016): Systematic review including reanalyses of 1148 individual data sets of central venous pressure as a predictor of fluid responsiveness. Intensive Care Med.; 42:324-332.

9. de Valley S, Olg TJ, Holman M, Ismael F, Ligtenberg JJM and ter Martin JC (2014): The caval index: an adequate non-invasive ultrasound parameter to predict fluid responsiveness in the emergency department? BMC Anesthesiology; 14:114.

10. Yanagawa $Y$, Sakamoto $T$, Okada $Y$ (2007): Hypovolemic shock evaluated by sonographic measurement of the inferior vena cava during resuscitation in trauma patients. J Trauma, 63(6):1245-1248.

11. Worapratya P, Anupat S, Suwannanon R, Wuthisuthimethawee P (2014): Correlation of caval index, inferior vena cava diameter, and central venous pressure in shock patients in the emergency room. Dovepress; 7:512-516

12. Shalaby M, Roshdy HM, Elmahdy WM, El Mezayen AEF (2018): Correlation between Central Venous Pressure and the Diameter of Inferior Vena Cava by using Ultrasonography for the Assessment of the Fluid Status in Intensive Care Unit Patients. The Egyptian Journal of Hospital Medicine; 72 (10): 5375-5384.

13. Ilyas A, Ishtiaq W, Assad S, Ghazanfar H, Mansoor S, Haris M (2017): Correlation of IVC Diameter and Collapsibility Index With Central Venous Pressure in the Assessment of Intravascular Volume in Critically Ill Patients. Cureus; 9(2): e1025. 


\section{دور قياس معدل التغير فى قطر الوريد الأجوف السفلى بواسطة الموجات فوق الصوتية مقابل قياس

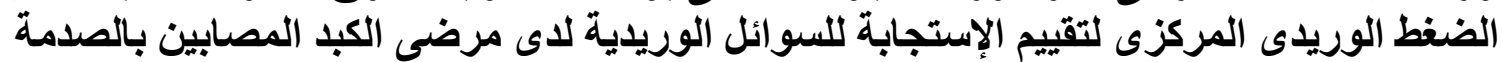

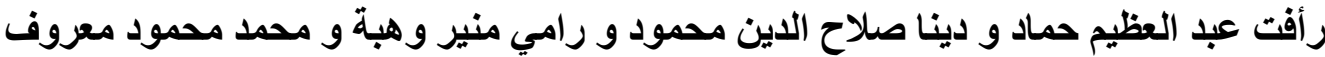

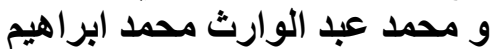

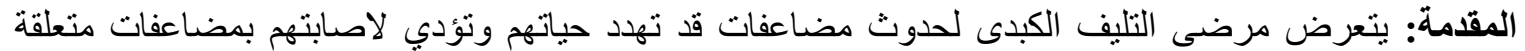

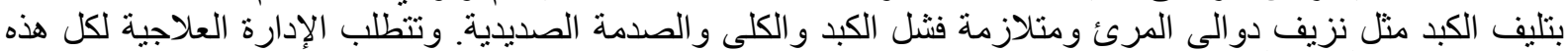

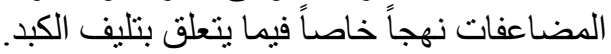

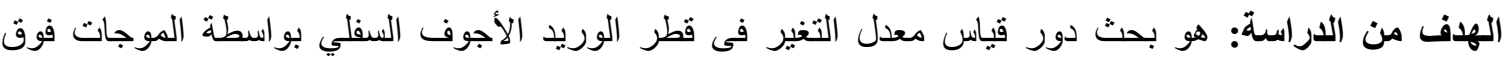

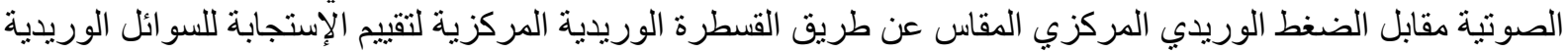
لدى مرضى الكبد المصابين بالصدمة.

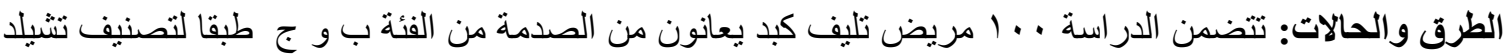

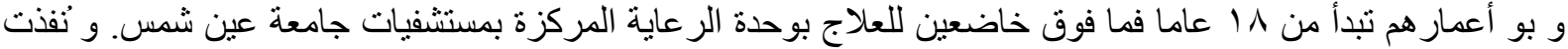

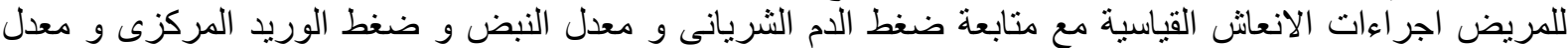

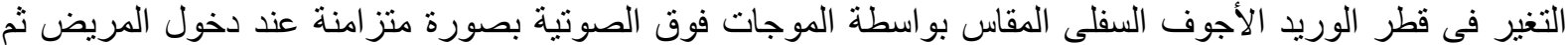
أثناء مر احل ادارة علاج الصدمة على فترات زمنية تالية بعد ساعة و أربع ساعات و ثمانى ساعات الصات.

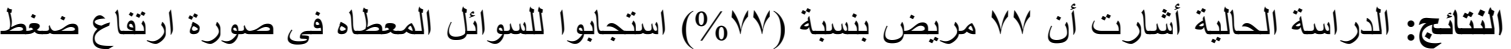

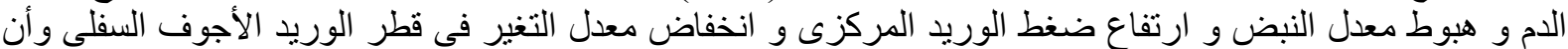

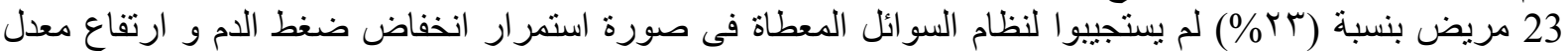

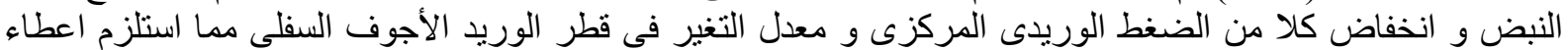
الأدوية الداعمة للدورة الدموية.

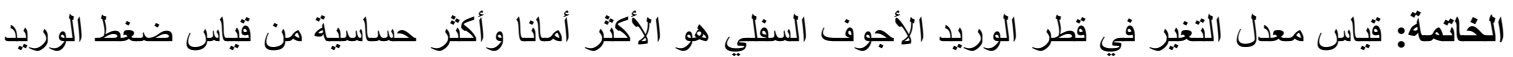

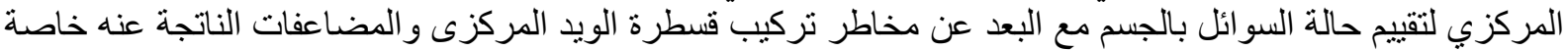

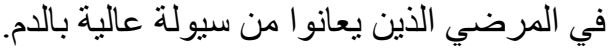

